\title{
Influence of Filler Metals in the Control of Deleterious Phases During the Multi-pass Welding of Inconel 718 Plates
}

\author{
K. Devendranath Ramkumar $\cdot$ R. Jagat Sai $\cdot$ G. Sridhar $\cdot$ V. Santhosh Reddy • \\ P. Prabaharan $\cdot$ N. Arivazhagan $\cdot$ N. Sivashanmugham
}

Received: 12 March 2014/Revised: 4 May 2014/Published online: 12 December 2014

(C) The Chinese Society for Metals and Springer-Verlag Berlin Heidelberg 2014

\begin{abstract}
The present study reported the effect of filler metals on the microstructure and mechanical properties of pulsed current gas tungsten arc-welded Inconel 718 plates. Two different filler metals such as ERNiCr-3 and ERNiCrMo-4 were employed for welding Inconel 718. The primary objective of this study is to suppress or eradicate the deleterious phase such as Laves or $\delta$ (delta) which is considered to be detrimental to the weld properties. Microstructure examination corroborated the presence of unmixed zone at the HAZ for both the weldments. Tensile test trials envisaged that ERNiCrMo-4 weldments offered better tensile properties compared to ERNiCr-3 weldments, whereas the impact toughness was found to be better for ERNiCr-3 weldments. Line mapping analysis was carried out to study the elemental migration across the weldments. The structure-property relationships of the weldments were arrived at using the combined techniques of optical and scanning electron microscopy. Optical and SEM/EDAX analysis showed that there is no prominent occurrence of deleterious phases at the weld zone on employing these filler metals.
\end{abstract}

\section{KEY WORDS: Inconel 718; Pulsed current gas tungsten arc welding; Mechanical property; Deleterious} phase

\section{Introduction}

Inconel 718 is a nickel base, precipitation hardenable alloy widely employed in aerospace applications. It was originally developed for gas turbine applications as an alloy with high strength and sluggish aging characteristics which can afford a high degree of metallurgical stability during fabrication [1]. Nickel-based superalloys such as Waspaloy

Available online at http://link.springer.com/journal/40195

K. Devendranath Ramkumar $(\bowtie) \cdot$ R. Jagat Sai · G. Sridhar

V. Santhosh Reddy $\cdot$ P. Prabaharan · N. Arivazhagan

School of Mechanical \& Building Sciences, VIT University,

Vellore, India

e-mail: deva@vit.ac.in

N. Sivashanmugham

Department of Mechanical Engineering, NIT, Tiruchirappalli, India and Inconel 718 are widely operated in high-temperature environments owing to their superior mechanical properties [2].

There are a few weldability issues related to Inconel 718 such as heat-affected zone (HAZ) micro-fissuring and solidification cracking, these problems could be solved on employing low heat input. Various reasons attributed to micro-fissuring in wrought Inconel 718 are constitutional liquation of $M C$ type carbides [3], boron-carbides and $\delta$ phase-assisted liquation cracking [4]. Prager and Shira [5] stated that Inconel 718 alloy was developed to overcome strain-age cracking while welding nickel-based superalloys. Use of $\mathrm{Nb}$ as an age hardener in place of $\mathrm{Al} / \mathrm{Ti}$ in Inconel 718 eliminated the problem of strain-age cracking but resulted in the formation of brittle Laves phase in the fusion zone.

The formation of brittle inter-metallic Laves phase in the inter-dendritic region by segregation during welding is one of the major problems addressed by various researchers 
$[6,7]$. Due to the segregation of $\mathrm{Nb}$ in the inter-dendritic region, the matrix is depleted of $\mathrm{Nb}$. $\mathrm{Nb}$ segregation and consequent formation of $\mathrm{Nb}$-rich, brittle, and inter-metallic Laves phase $\left((\mathrm{Ni}, \mathrm{Fe}, \mathrm{Cr})_{2}(\mathrm{Nb}, \mathrm{Mo}, \mathrm{Ti})\right)$ during weld metal solidification depletes the matrix of useful alloying elements and aids in easy crack initiation and propagation $[8,9]$.

Laves phase could develop in either fusion zone (FZ) or HAZ of Inconel 718 after welding [10-14]. Laves phase affects the tensile and rupture properties, ductility, fracture toughness, and fatigue life of the welded components.

Radhakrishna et al. [9] reported that the weld cooling rate/heat input has more influence in controlling the microsegregation and consequent formation of Laves phase in the weld metals. As evident from the literatures, segregation is a time-dependent phenomenon and is strongly affected by the weld cooling rate, heat input, welding process, etc. Further the authors stated that slow weld cooling rates result in relatively large dendritic arm spacings compared to rapidly cooled welds, and these coarse dendritic spacings provide congenial/preferential sites for segregation of alloying elements during weld solidification. Even from this point of view, slowly cooled GTA welds are more prone to segregation.

The presence of Laves phase in cast base metal was also found to reduce the weldability of the material by causing micro-fissuring during welding. Studies by Carlson and Radavich [15] have shown that even in solution-treated castings, the elemental segregation diminishes very little, resulting in a microstructure that is optically homogeneous, but almost as segregated as the original casting and prone to formation of low-melting phases and cracks during the weld thermal cycle. Manikandan et al. [7] found the beneficial effect of helium gas with compound current pulse mode on the control of Laves phase in the GTA fusion zone of Inconel 718. Zhang et al. [16, 17] has reported significant refinement in the microstructure of the superalloy and reduced micro-segregation at the weld interface. It was reported by Manikandan et al. [7] that pulsed current GTA welding technique has shown better results in terms of $\mathrm{Nb}$ segregation in the inter-dendritic regions compared to electron beam (EB) welding process using different oscillation techniques.

As evident from the literatures, Inconel 718 is weldable by various methods [18-23]. However, the formation of Laves phase is inevitable unless heat input is controlled during welding. It is also evident that the use of current pulsing resulted in significant refinement of the fusion zone solidification structure with consequent improvement in Laves morphology. However, less published information on the use of current pulsing GTA welding for joining Inconel 718 and substantial control of Laves phase formation is available. Moreover, not many studies have been reported on the effect of filler metals in the control of deleterious phases which significantly affects the mechanical properties of Inconel 718. This paper addresses the influence of filler metals in metallurgical and mechanical properties of pulsed current gas tungsten arc-welded Inconel 718. The details of the experimental procedure are outlined in the following chapters.

\section{Experimental}

\subsection{Base Metal and Welding Procedure}

The chemical composition of the base and filler metals is carried out using dry spectroscopic methods and is represented in Table 1. The as-received hot rolled base metal has the dimensions of $500 \mathrm{~mm} \times 500 \mathrm{~mm} \times 5 \mathrm{~mm}$. The plates were machined to $170 \mathrm{~mm} \times 55 \mathrm{~mm} \times 5 \mathrm{~mm}$ using wire-cut electrical discharge machining (EDM) to carry out welding. The process parameters were established after conducting iterative studies based on bead on plate welding and also by trial runs; the optimal parameters employed for multi-pass PCGTA welding of Inconel 718 is shown in Table 2. The filler metals employed in this study are ERNiCr-3 and ERNiCrMo-4. The plates were prepared to a standard V-groove butt joints with an included angle of $70^{\circ}$ and a root face of $1 \mathrm{~mm}$ was employed for welding. A specially designed fixture with a copper back plate was employed to clamp the base metals firmly and also to avoid distortion and bending while welding. After welding, the weldments were characterized for gamma ray NDT examination to determine any flaws, porosities, undercut, etc.

\subsection{Metallurgical and Mechanical Characterization Studies}

Followed by NDT analysis, the PCGTA weldments were sliced using wire-cut EDM to obtain different coupons of various standard dimensions to assess the metallurgical and mechanical properties. The macro and microstructure examination and hardness studies were performed on the coupons having dimensions of $30 \mathrm{~mm} \times 10 \mathrm{~mm} \times 5 \mathrm{~mm}$ termed as "composite regions" which cover all the zones of the weldment. These samples were polished using $\mathrm{SiC}$ emery sheets of various grit sizes from 220 to 1,000 which were then followed by disk polishing using alumina solution so as to obtain a mirror finish of $1 \mu$ on the weldments. Electrolytic etching (10\% oxalic acid; 7 V DC supply and $1 \mathrm{~A} \mathrm{~cm}^{-2}$ ) was employed to examine the microstructure at the various zones of Inconel 718.

Furthermore to investigate the mechanical properties of the weldments, the coupons were cut as per the standards. Tensile studies were performed on the weldments which 
Table 1 Chemical compositions of the base and filler metals (wt\%)

\begin{tabular}{|c|c|c|c|c|c|c|c|c|c|}
\hline Metal & $\mathrm{C}$ & $\mathrm{Si}$ & Mn & $\mathrm{Cr}$ & $\mathrm{Ni}$ & $\mathrm{Nb}$ & Mo & $\mathrm{Fe}$ & Others \\
\hline Inconel 718 & 0.026 & 0.102 & 0.085 & 17.49 & Bal. & 5.03 & 2.96 & 20.3 & $\begin{array}{l}\text { P 0.009; Cu 0.025; } \\
\text { Al 0.572; Ti 0.905; } \\
\text { Ta }<0.02 ; \mathrm{N}<0.005 \\
\text { Co } 0.102\end{array}$ \\
\hline ERNiCr-3 & 0.02 & 0.1 & 3.1 & 20.5 & Bal. & 2.6 & - & 1.0 & P 0.002; Ti 0.5; S 0.09; Cu -0.5 \\
\hline ERNiCrMo-4 & 0.02 & 0.08 & 1.0 & 15.5 & Bal. & - & 16.0 & 4.5 & P 0.04 ; S 0.03 ; Cu 0.25 ; Co 1.1 ; W 3.5 \\
\hline
\end{tabular}

Table 2 Process parameters employed for PCGTA welding of Inconel 718

\begin{tabular}{|c|c|c|c|c|c|c|c|}
\hline \multirow[t]{2}{*}{ Filler } & \multirow{2}{*}{$\begin{array}{l}\text { Number } \\
\text { of pass }\end{array}$} & \multirow[t]{2}{*}{ Voltage (V) } & \multicolumn{2}{|l|}{ Current (A) } & \multirow{2}{*}{$\begin{array}{l}\text { Pulse } \\
\text { frequency }(\mathrm{Hz})\end{array}$} & \multirow{2}{*}{$\begin{array}{l}\text { Shielding gas } \\
\text { flow rate }(\mathrm{L} / \mathrm{min})\end{array}$} & \multirow{2}{*}{$\begin{array}{l}\text { Filler wire } \\
\text { diameter }(\mathrm{mm}\end{array}$} \\
\hline & & & Background current & Peak current & & & \\
\hline ERNiCrMo-4 & 4 & $12.8-16.1$ & 160 & 213 & 7.5 & 15 & 2.4 \\
\hline ERNiCr-3 & 4 & $11.6-14.5$ & 160 & 213 & 7.5 & 15 & 2.4 \\
\hline
\end{tabular}
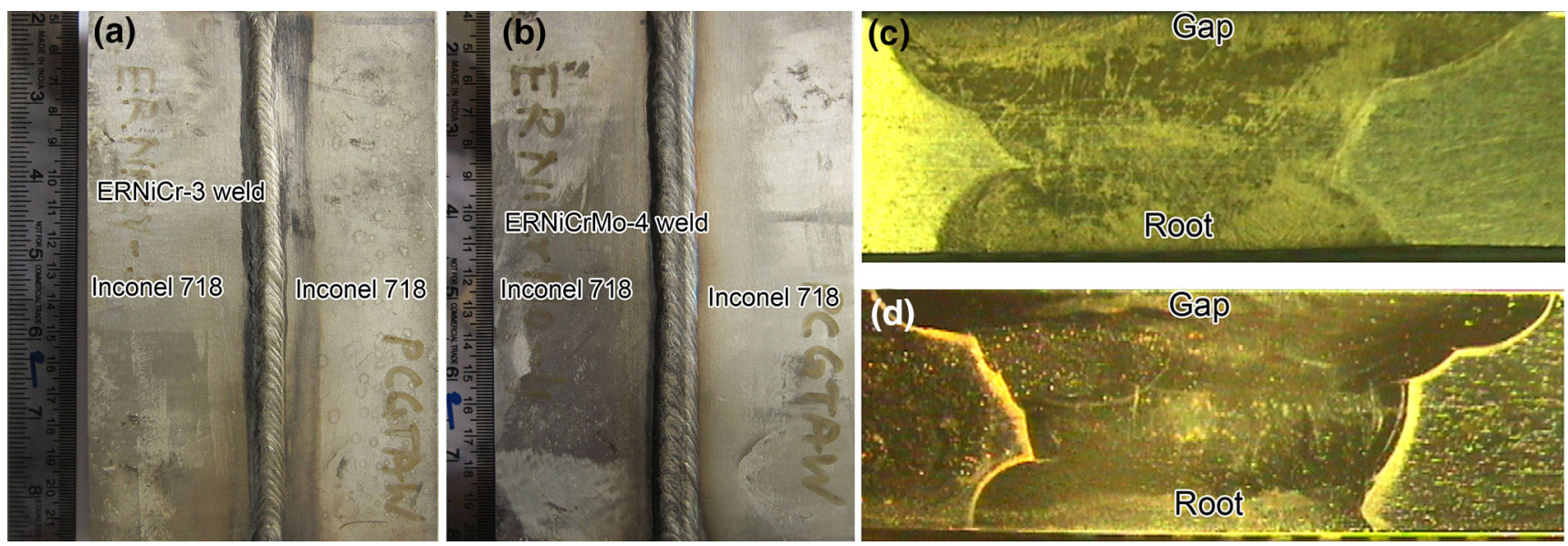

Fig. 1 a Photographs and the macrostructures of the PCGTA welded Inconel 718 plates employing ERNiCr-3 and ERNiCrMo-4 fillers: a, c ERNiCr-3 filler; b, d ERNiCrMo-4 filler

were prepared as per ASTM E8/8M standards. Two test trials on the weldments were conducted to check the reproducibility of the results. The samples were tested at a strain rate of $2 \mathrm{~mm} / \mathrm{min}$ at room temperature. Charpy $\mathrm{V}$-notch impact test samples were prepared and tested according to the ASTM E23-12C standards of sub-sized specimens. The fractured samples were characterized for SEM analysis to determine the mode of fracture. Hardness measurement was carried out on the composite region of the weldments using Vicker's Micro-hardness tester with a load of $4.9 \mathrm{~N}$ for a dwell time period of $10 \mathrm{~s}$ at regular intervals of $0.25 \mathrm{~mm}$. Measurements were carried out on three distinct zones vis-à-vis cap, filler pass, and root of the weldments. Further the SEM/EDS analysis was performed on the various zones of the weldments to determine the presence of various elements and assess the structure-property correlations. The following chapter addresses the results and discussions of the experimental work.

\section{Results}

\subsection{Macro and Microstructure Examination}

It is clear from the visual examination and macro-structure studies that PCGTA welding could be employed for joining Inconel 718 employing ERNiCr-3 and ERNiCrMo-4 filler metals. Both the filler wires and the established process parameters have assented better weld bead (Fig. 1) by 

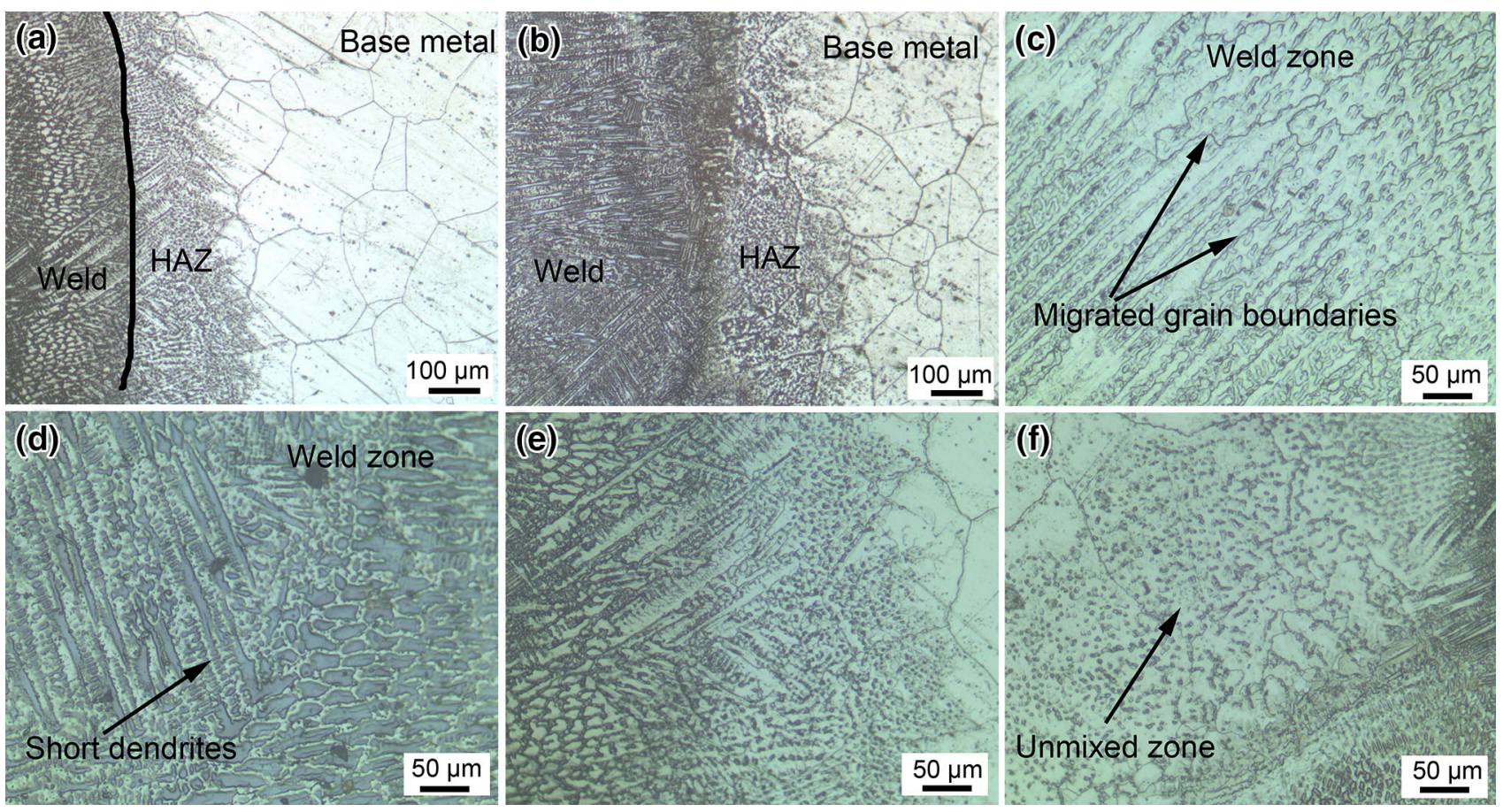

Fig. 2 Microstructures SEM images showing the microstructures of PCGTA weldments emplying ERNiCr-3 a, c, e; ERNiCrMo-4 b, d, f fillers: a, b composite zone; $\mathbf{c}, \mathbf{d}$ weld zone; e, f HAZ
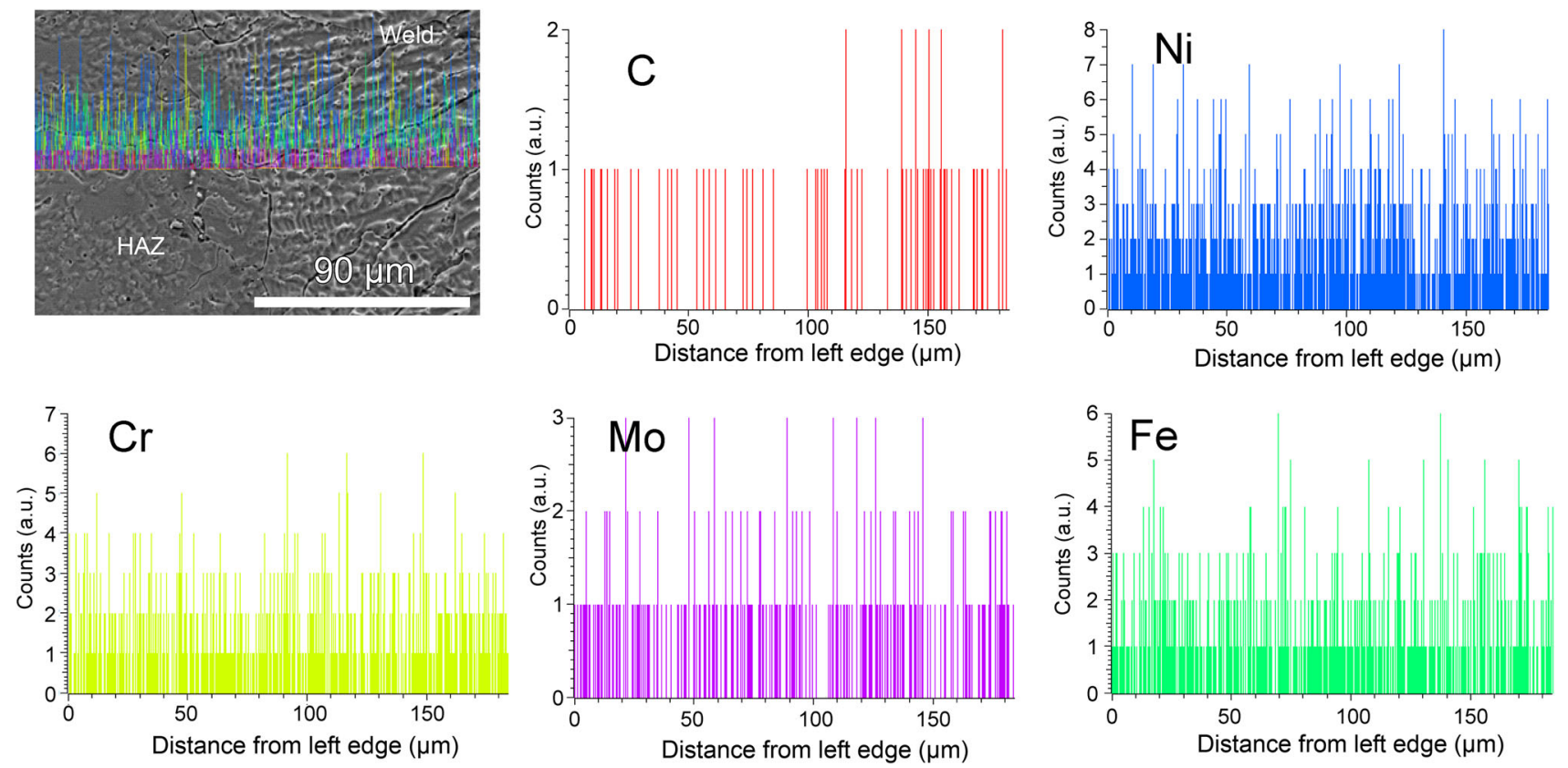

Fig. 3 Line mapping analysis on the as-welded PCGTA weldments of Inconel 718 employing ERNiCr-3 filler

showing proper fusion with the base metals. No physical surface defects like arc strike, cracks, and undercut have been observed in any of these weldments. Also gamma ray NDT inspection clearly showed that the weldments were free from subsurface weld defects such as inclusions, porosity, lack of fusion, etc.
The optical micrographs of the various zones of the PCGTA-welded Inconel 718 employing two different filler metals are shown in Fig. 2. Microstructure examination revealed the formation of secondary phases or the presence of unmixed zone at the HAZ of Inconel 718 for both the filler metals. Migrated grain boundaries (MGBs) (Fig. 2c) have 

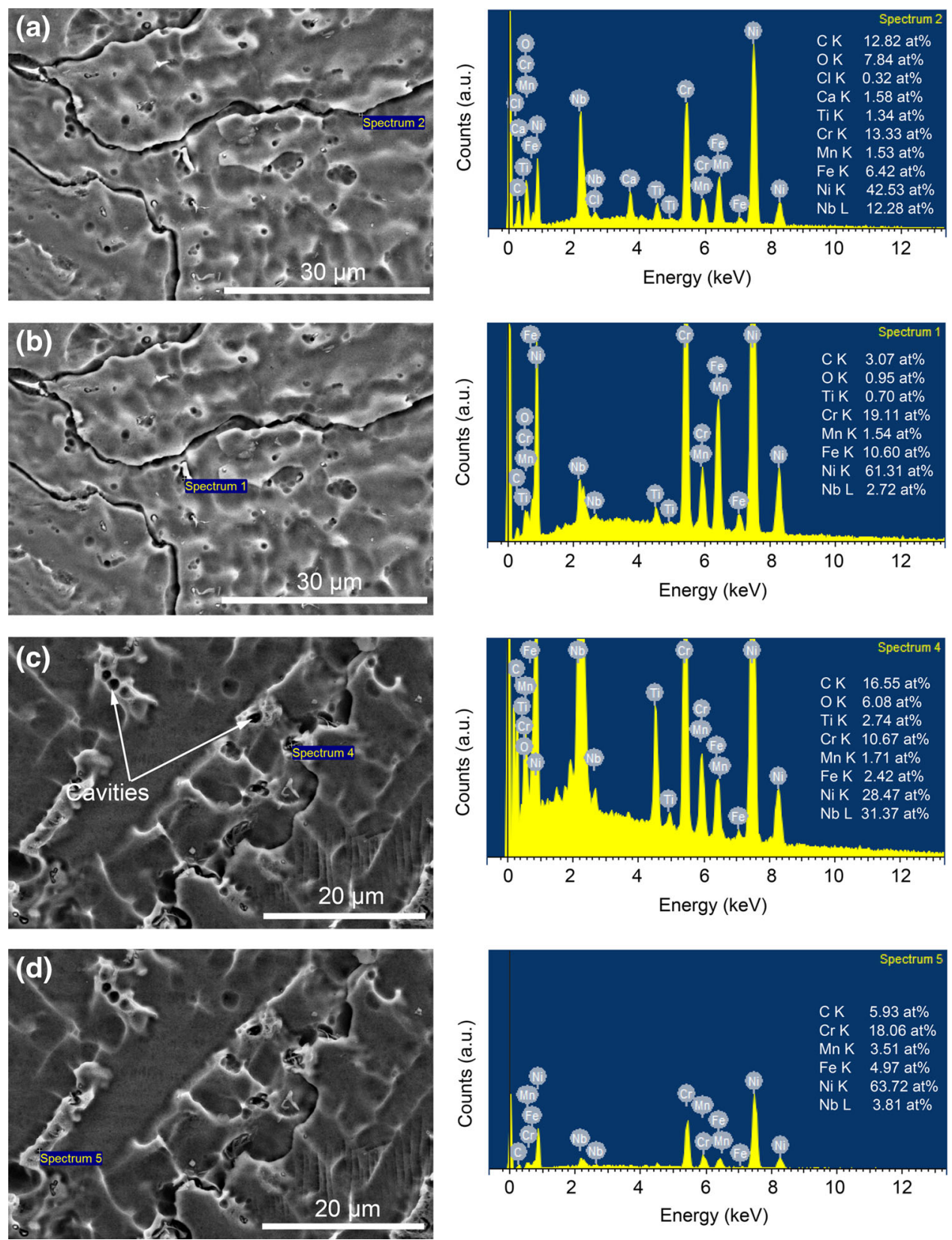

Fig. 4 SEM images and EDS analysis results on HAZ $\mathbf{a}, \mathbf{b}$ and weld zones $\mathbf{c}, \mathbf{d}$ of the Inconel 718 weldments employing ERNiCr-3 filler

been observed at the weld zone while employing ERNiCr-3, whereas multi-directional grain growth containing cellular and dendritic structures with the protuberance of smaller arms (Fig. 2d) resulted on using ERNiCrMo-4. Further line mapping analysis was carried out on the weldments to investigate for elemental migration.

\subsubsection{SEM/EDS Analysis on the PCGTA Weldments Employing ERNiCr-3}

Line mapping shown in Fig. 3 substantiated that the elemental migration was found to be meager from the weld to
HAZ or vice versa. However, the interface has shown greater amounts of $\mathrm{Cr}, \mathrm{Ni}$, and $\mathrm{Fe}$. The line spectra clearly indicated the presence of $\mathrm{C}$ and Mo to be lesser at the weld interface.

Figure 4 illustrates the microstructures and EDS results of the HAZ and weld zone of the specimen employing ERNiCr-3 filler. It is inferred from the point EDS analysis results that the matrix of HAZ consists of enriched amounts of $\mathrm{Ni}, \mathrm{Nb}, \mathrm{Cr}$, and $\mathrm{Fe}$ and considerable amounts of $\mathrm{Ti}, \mathrm{Mn}$ (Fig. 4a, b), and the weld zone consists of $\mathrm{Ni}, \mathrm{Nb}$, and $\mathrm{Cr}$ (Fig. 4c, d). The voids or cavities were observed on the dendritic arms of the weld zone. $\mathrm{Nb}$ and $\mathrm{Ni}$ constituents are 

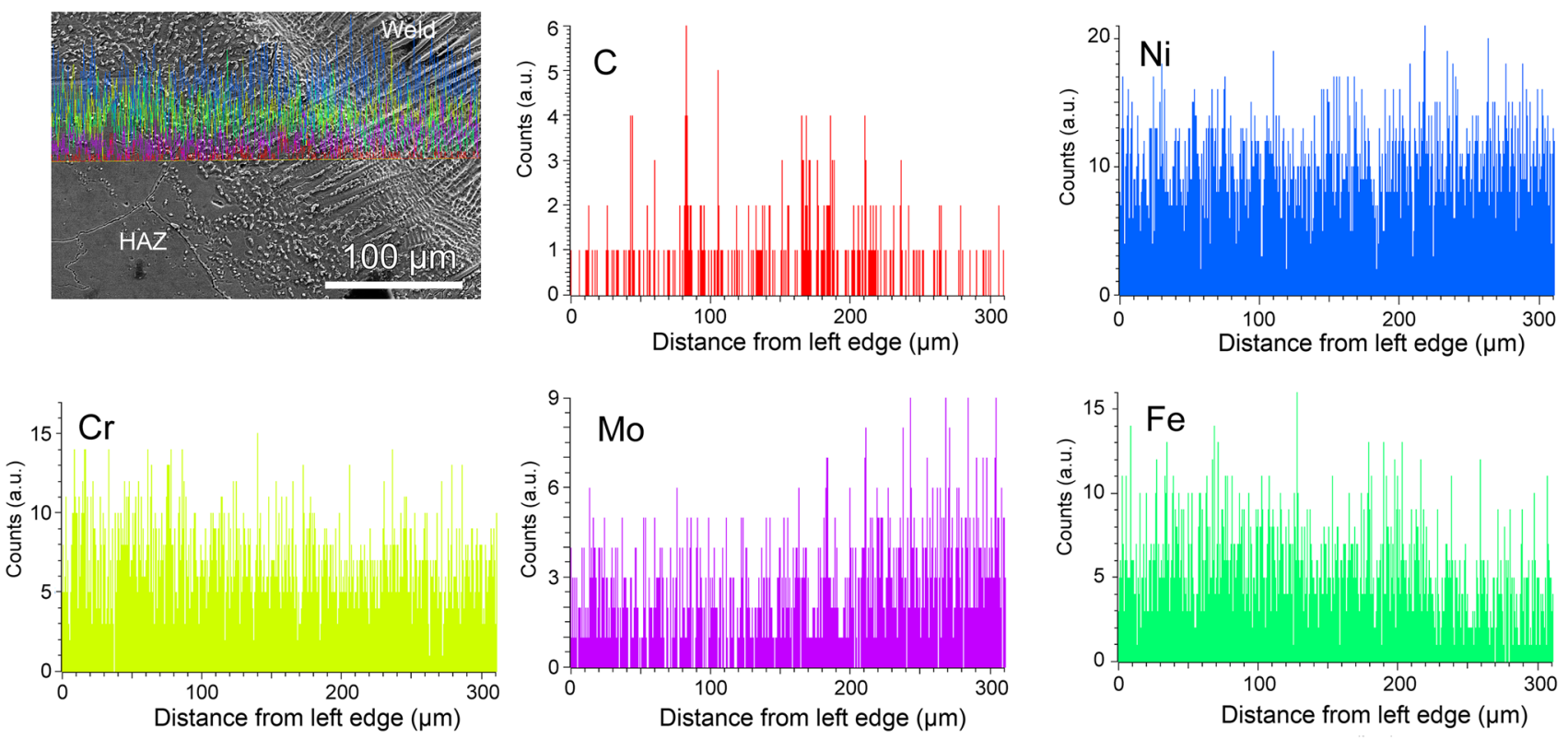

Fig. 5 Line mapping analysis on the as-welded PCGTA weldments of Inconel 718 employing ERNiCrMo-4 filler

found to be more at the dendritic arm, whereas the matrix of the weld has lower constituents of $\mathrm{Nb}$.

\subsubsection{SEM/EDS Analysis on the PCGTA Weldments Employing ERNiCrMo-4}

The EDS line mapping analysis depicted that the elemental migration across these weldments was very less (Fig. 5). It was observed that the matrix of the HAZ consists of $\mathrm{Ni}, \mathrm{Cr}$, and $\mathrm{Fe}$ in greater amounts whereas $\mathrm{Nb}, \mathrm{Mo}, \mathrm{Al}$, and $\mathrm{Ti}$ were found in lesser amounts.

Figure 6 illustrates the microstructures and EDS results of the HAZ and weld zone of the specimen employing ERNiCrMo-4 filler. The point EDS analysis results indicate that the secondary phases in the HAZ have been enriched with $\mathrm{Ni}, \mathrm{Nb}, \mathrm{Cr}, \mathrm{C}$, and $\mathrm{Fe}$; the presence of $\mathrm{Al}, \mathrm{Ti}$, and $\mathrm{Si}$ was also observed (Fig. 6a, b). The weld matrix consists of greater amounts of $\mathrm{Ni}, \mathrm{Mo}, \mathrm{Nb}, \mathrm{Cr}$, and $\mathrm{Fe}$ (Fig. 6c). The void spaces at the weld zone have been occupied with the secondary phase with richer constituents of $\mathrm{Ni}, \mathrm{Nb}, \mathrm{Ti}, \mathrm{Cr}$, and Fe (Fig. 6d).

\subsection{Mechanical Characterization of Weldments}

\subsubsection{Hardness Measurements}

Hardness computations were carried out in different passes of the welding and the hardness trend is shown in Fig. 7, also the values are tabulated in Table 3. Distinct variations in hardness profile at the different passes of ERNiCr-3 weldments have been noticed. The average hardness values exhibited at the weld zone of ERNiCr-3 weldments are 211.7 HV, 229.5 HV, and 236.4 HV on the cap, filler pass, and root zones, respectively, and the peak hardness value at the weld zone is witnessed to be $281.2 \mathrm{HV}$.

There is not much variation in the hardness profile across the various passes of ERNiCrMo- 4 weldments. The average hardness value at the weld zone is observed to be 237.3, 238.6, and $238 \mathrm{HV}$ at the cap, filler pass, and the root pass, respectively. The peak hardness value of 282.6 HV is witnessed at the cap zone, whereas the hardness values at the filler and root were observed to be 265.9, $267.8 \mathrm{HV}$, respectively.

\subsubsection{Tensile and Impact Studies}

Tensile properties of the PCGTA-welded Inconel 718 employing ERNiCr-3 and ERNiCrMo-4 filler metals are shown in Table 4. Tensile studies apparently showed that the fracture occurred at the weld zone for ERNiCr-3 weldments and the parent metal for ERNiCrMo-4 weldments (Fig. 8) in all the trials. The fractured samples gave an insight into the idea that plastic deformation had occurred before rupture. It was observed that the average tensile strength of PCGTA weldments employing ERNiCrMo-4 (725 MPa) was better as compared to ERNiCr-3 filler (688.5 MPa). Further the SEM analysis of the fractured tensile samples clearly dictated the formation of micro-voids and dimples for ERNiCr-3 weldments, whereas voids of larger dimensions and minute dimples are 

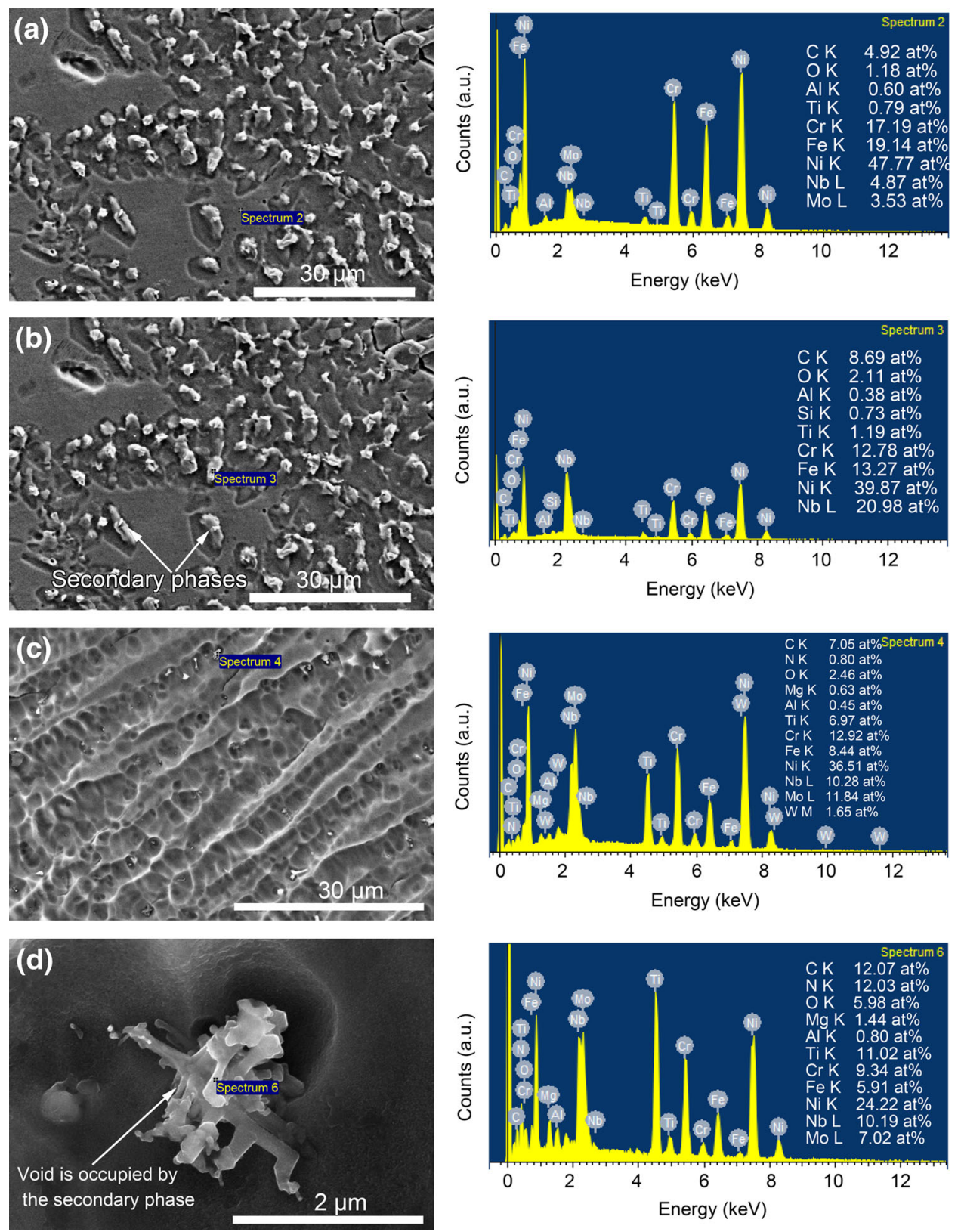

Fig. 6 SEM images and EDS analysis results on HAZ a, b; weld zones $\mathbf{c}, \mathbf{d}$ of the Inconel 718 weldments employing ERNiCrMo-4 filler

present in random locations in case of ERNiCrMo-4 weldments (Fig. 8c, d).

Impact tests of weldments are vital especially in aerospace applications as they are usually subjected to high impact forces during their service conditions. Charpy impact studies envisaged that the PCGTA weldments employing ERNiCr-3 filler exhibited better impact strength (63 J) compared to ERNiCrMo-4 filler metal $(51 \mathrm{~J})$. The values of impact studies are outlined in Table 5. As evident from the fractured samples shown in Fig. 9, the mode of failure is observed to be ductile for both the filler metals.

\section{Discussion}

It is well surmised that sound welds of Inconel 718 have been achieved on employing PCGTA welding using both the filler metals ERNiCr-3 and ERNiCrMo-4. It was also divulged from the gamma ray NDT analysis and macrostructure studies (Fig. 1) that there were no weld defects including porosities, undercut, and lack of fusion on employing these filler metals.

Microstructure studies depicted the formation of secondary phases at the HAZ of Inconel 718 while employing 

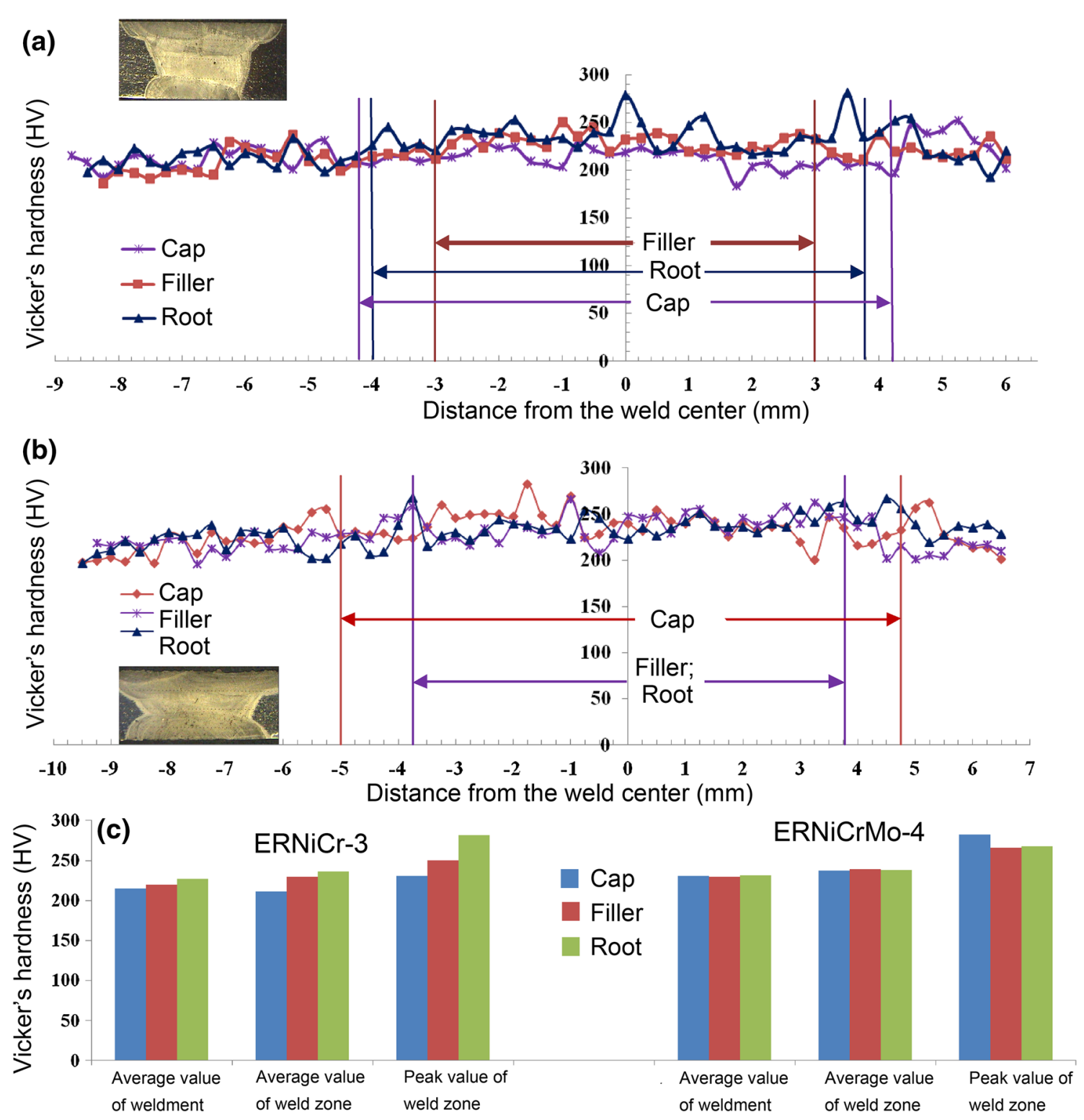

Fig. 7 Vicker's micro-hardness curves of the PCGTA welded Inconel 718 samples employing ERNiCr-3 a; ERNiCrMo-4 b fillers, comparison chart of hardness of the weldments $\mathbf{c}$

these filler metals. Segregation is observed to be more prominent at the HAZ employing ERNiCrMo-4 filler. MGBs are observed at the weld zone of ERNiCr-3 welds. This could be understood from the fact that MGBs are formed on fully austenitic welds. Migration of boundary is possible during reheating, such as during multi-pass welding and while using Ni-rich filler metals [24]. Short dendrites and cellular growth are observed at the weld zone during the multi-pass PCGTA welding employing ERNiCrMo-4 filler. The short arm, equi-axed dendritic growth is quite normal while welding Inconel 718 using current pulsing. This is well in agreement with the studies of Manikandan et al. [7] in current pulsing pattern, where two levels of temperature gradient are introduced, promoting constitutional super cooling in short span and reduced time at temperature of the molten pool. This leads to reduction in temperature gradient and promotes equiaxed dendrites. In each level of pulse pattern, there exists a steep temperature gradient that leads to higher cooling rate and in turn resulting in reduced dendrite arm spacing.

Both the optical and scanning electron microscopy corroborated the fact on the absence of Laves phase at the weld zone. Radhakrishna et al. [9] reported that formation of Laves phase is of major concern and a significant challenge in welding of IN 718, especially when using high heat input processes like GTAW, which are more prone to segregation due to their slow cooling rate characteristics. SEM/EDAX analysis (Fig. 4c, d) had clearly shown the 
Table 3 Hardness values of different positions of the Inconel 718 weldments

\begin{tabular}{|c|c|c|c|c|}
\hline Filler & Description & Cap & Filler & Root \\
\hline \multirow[t]{3}{*}{ ERNiCr-3 } & $\begin{array}{l}\text { Average hardness of the } \\
\text { weldment }\end{array}$ & 214.7 & 219.7 & 227.0 \\
\hline & $\begin{array}{l}\text { Average hardness at the weld } \\
\text { zone }\end{array}$ & 211.7 & 229.5 & 236.4 \\
\hline & $\begin{array}{l}\text { Peak hardness at the weld } \\
\text { zone }\end{array}$ & 230.2 & 249.9 & 281.2 \\
\hline \multirow[t]{3}{*}{ ERNiCrMo-4 } & $\begin{array}{l}\text { Average hardness of the } \\
\text { weldment }\end{array}$ & 230.4 & 229.5 & 231.4 \\
\hline & $\begin{array}{l}\text { Average hardness at the weld } \\
\text { zone }\end{array}$ & 237.3 & 238.6 & 238.0 \\
\hline & $\begin{array}{l}\text { Peak hardness at the weld } \\
\text { zone }\end{array}$ & 282.6 & 265.9 & 267.8 \\
\hline
\end{tabular}

Table 4 Tensile properties of the Inconel 718 Weldments with different fillers

\begin{tabular}{|c|c|c|c|c|c|c|}
\hline \multirow[t]{2}{*}{ Property } & \multicolumn{3}{|c|}{ ERNiCr-3 } & \multicolumn{3}{|c|}{ ERNiCrMo-4 } \\
\hline & $\begin{array}{l}\text { Trial } \\
1\end{array}$ & $\begin{array}{l}\text { Trial } \\
2\end{array}$ & Average & $\begin{array}{l}\text { Trial } \\
1\end{array}$ & $\begin{array}{l}\text { Trial } \\
2\end{array}$ & Average \\
\hline $\begin{array}{l}\text { Maximum load } \\
(\mathrm{kN})\end{array}$ & 19.8 & 20.5 & 20.2 & 21.1 & 21.2 & 21.2 \\
\hline $\begin{array}{l}\text { Maximum tensile } \\
\text { strength }(\mathrm{MPa})\end{array}$ & 677 & 700 & 688.5 & 726 & 724 & 725 \\
\hline $\begin{array}{l}\text { Young's modulus } \\
\text { (GPa) }\end{array}$ & 59.8 & 57.1 & 58.5 & 53.2 & 50.3 & 51.8 \\
\hline $\begin{array}{l}\text { Tensile strain at } \\
\text { break }(\%)\end{array}$ & 64.5 & 68.1 & 66.3 & 78.1 & 76.1 & 77.1 \\
\hline Fracture zone & \multicolumn{3}{|c|}{ Weld region } & \multicolumn{3}{|c|}{$\begin{array}{l}\text { Parent metal } \\
\text { of Inconel } 718\end{array}$} \\
\hline
\end{tabular}

presence of higher amounts of $\mathrm{Nb}, \mathrm{Ni}, \mathrm{Cr}$, and $\mathrm{C}$. As the Mo constituent is absent in the filler wire ERNiCr-3, it has not appeared in the weld zone. Hence the formation of deleterious phases such as Laves, $\delta$ is not witnessed at the welds. The formation of phases such as $\mathrm{NbC}, \mathrm{M}_{23} \mathrm{C}_{6}$, precipitation of $\gamma^{\prime}-\mathrm{Ni}_{3}(\mathrm{Ti})$ is expected at the weld zone employing ERNiCr-3. Further to confirm the formation of these aforementioned phases, X-Ray Diffraction (XRD) and EPMA (Electron Probe Micro-analyzer) analysis are required. Cieslak et al. [13] reported that the solidification metallurgy of Alloy 718 (and other Nb-bearing superalloys) is dominated by the segregation behavior of $\mathrm{Nb}$ and the formation of Nb-rich, eutectic-like constituents of the form $\gamma /$ Laves and $\gamma / M C(\mathrm{NbC})$.

Similarly, there is no evidence of formation of deleterious phases at the weld zone of ERNiCrMo-4 weldments. The HAZ of these weldments have typical formation of secondary phases containing enriched constituents of $\mathrm{Ni}$, $\mathrm{Nb}$. Also the weld zone showed the presence of typical constituents of $\mathrm{Ni}, \mathrm{Nb}, \mathrm{Mo}, \mathrm{Cr}$, and $\mathrm{W}$. However, these elements are not found to be segregated at the inter-dendritic arms of the weld zone. Figure $6 \mathrm{~d}$ shows the presence of secondary phase at the void space of the weld zone. This secondary phase consists of enriched amounts of $\mathrm{Ni}, \mathrm{Ti}$, $\mathrm{Nb}, \mathrm{Mo}, \mathrm{W}$, and $\mathrm{Fe}$ which would have probably formed strong inter-metallic compounds such as $\mathrm{NbC},(\mathrm{Nb}, \mathrm{Ti}) \mathrm{C}$, $\mathrm{Ni}_{3}(\mathrm{~A} 1, \mathrm{Ti})$, WC. From the SEM observations, it is clear that the deleterious delta or Laves phases have not been formed in these instances. The microstructure results evidently authenticated the absence of deleterious phases such as Laves, needle-shaped $\delta$ precipitates [6] due to the current pulsing and the proper selection of filler wires. This could be well supported with the research findings of Radhakrishna et al. [9] that the formation of Laves phase could be controlled by several ways that include: (i) employing current pulsing; (ii) use of filler wires with low concentrations of $\mathrm{Nb}, \mathrm{Cr}, \mathrm{Fe} \mathrm{Mo}$ and $\mathrm{Si}$; (iii) using homogenizing heat treatments; (iv) steep thermal gradients. However, the absence of deleterious phase could be confirmed clearly with the EPMA and TEM analysis which requires further investigation.

Hardness profile clearly envisaged that the average hardness of the ERNiCrMo-4 weldments in different passes is found to be more as compared to ERNiCr-3 weldments (Table 3). Further it is opined there were not much differences in the hardness values exhibited in the weld zone and parent metal. The enhanced hardness exhibited in the ERNiCrMo-4 weldments is due to the probable formation of strong inter-metallic compounds as discussed which is also evident from the SEM/EDAX analysis (Fig. 6).

Tensile tests showed that the ultimate tensile strength was found to be better for ERNiCrMo-4 weldments and also that the fracture occurred at the parent metal side. However, the Young's moduli values are found to be lower. As reported by Davis [25], tensile tests could also measure the elastic modulus. However, the elastic modulus is not sensitive to the differences between weld, HAZ, and base metal in rare cases. The author further specified that the tensile testing procedures for welded joints cannot be relied upon, to provide accurate values of elastic modulus. It could be further explained that there is a mismatch in the thermal expansion coefficients and chemical composition of the base and filler metals and also that multi-pass welding would have resulted in the residual stresses and distortion. The presence of residual stresses have significant, however, small amounts of influence on the yield stress and young's modulus. From the results, it is evident that there is no typical formation of Laves and/or $\gamma^{\prime \prime}$ phases which are reported as deleterious phases responsible for lowering the ductility and strength of the welds. On the other hand, the tensile fracture has been observed at the weld zone in case of ERNiCr-3 weldments. However, 

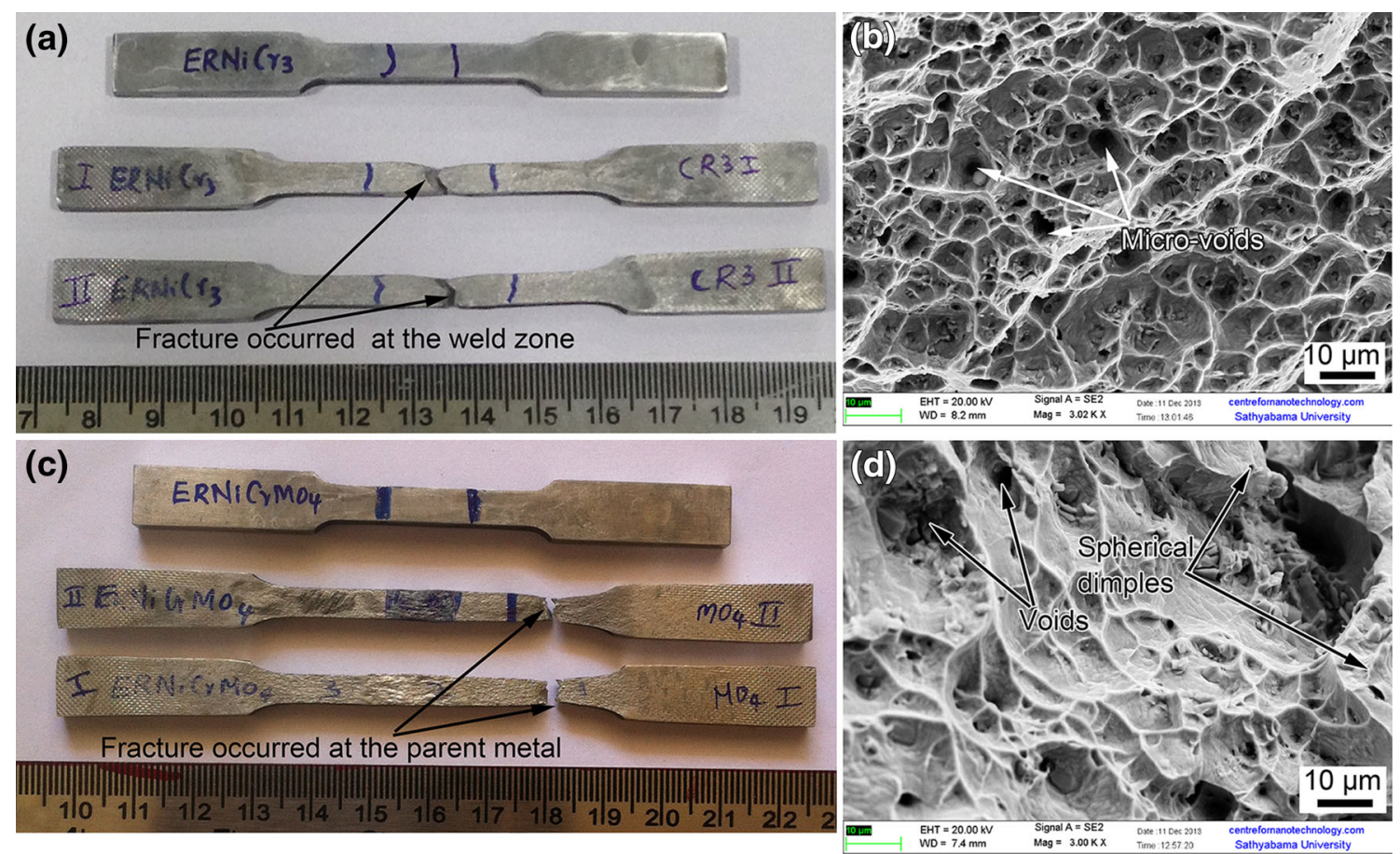

Fig. 8 Fractured tensile samples and SEM fractographs of Inconel 718 weldments employing ERNiCr-3 a, b; ERNiCrMo-4 c, d fillers

Table 5 Impact properties of the Inconel 718 weldments with different fillers

\begin{tabular}{|c|c|c|c|c|c|c|}
\hline \multirow[t]{2}{*}{ Property } & \multicolumn{3}{|c|}{ ERNiCr-3 } & \multicolumn{3}{|c|}{ ERNiCrMo-4 } \\
\hline & Trial 1 & Trial 2 & Average & Trial 1 & Trial 2 & Average \\
\hline $\begin{array}{l}\text { Impact } \\
\text { energy } \\
(\mathrm{J})\end{array}$ & 70 & 56 & 63 & 48 & 54 & 51 \\
\hline $\begin{array}{c}\text { Fracture } \\
\text { mode }\end{array}$ & Ductile & & & Ductile & & \\
\hline
\end{tabular}

severe plastic deformation had occurred before the failure which is evident from the tensile photographs shown in Fig. 8. Voids or cavities observed at the weld zone of these ERNiCr-3 weldments could be reasoned out by the depletion of low-melting eutectic phases. It was reported by several researchers $[1,7,18-23]$ that the presence of Laves phase at the weld zone deteriorate the ductility of the weld joints and catastrophic failures shall be expected in the welded structures. As depicted earlier, the microstructure of ERNiCrMo-4 weldments revealed the presence of strong inter-metallic compounds which contributed for better strength and hardness. Further the SEM fractographies (Fig. 8c, d) acquiesced the presence of micro/macrovoids and dimples with the formation of ductile tear ridges confirming a ductile mode of fracture. The presence of macro-voids portrayed in the SEM clearly envisaged that more energy had been absorbed before and during rupture.
This is also reassuring the absence or reduction of deleterious phases.

Charpy V-notch impact test results at room temperatures demonstrated that the weldments exhibited lower toughness compared to the parent metal. However, on comparing the filler metals, the average impact toughness is found to be greater for ERNiCr-3 weldments. It could be well understood that the average hardness of the weldments employing ERNiCr-3 filler is lower than ERNiCrMo-4 weldments. Hence it is indicated that the impact toughness is slightly greater for ERNiCr-3 weldments as toughness and hardness are inversely proportional.

From the investigations, it is summarized in a nutshell that the current pulsing and the use of filler metals ERNiCr-3 and ERNiCrMo-4 is effective in controlling the deleterious phases during the multi-pass welding of Inconel 718 as indicated by the results obtained from the tensile and impact studies. However, further investigations including EPMA and TEM analysis are required to nourish the validation of the results.

\section{Conclusions}

1. Sound welds of Inconel 718 could be obtained by multi-pass PCGTA welding employing ERNiCr-3 and ERNiCrMo-4 filler. 

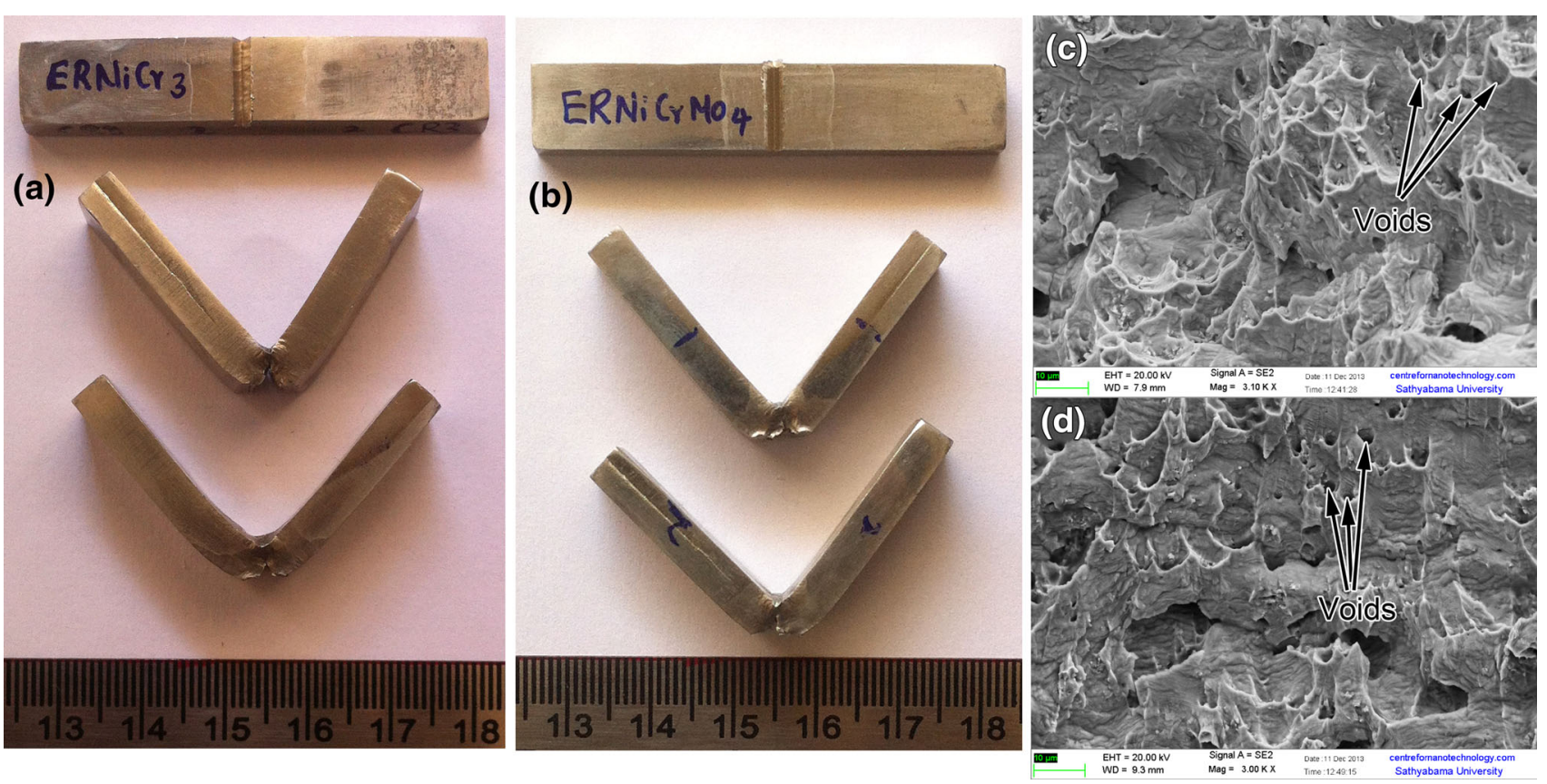

Fig. 9 Impact test samples and corresponding SEM fractographs of Inconel 718 weldments employing ERNiCr-3 a, c; ERNiCrMo-4 b, d fillers

2. Microstructure studies corroborated the formation of secondary phases at the heat-affected zones in both the weldments; MGBs were more prevalent at the weld zone of ERNiCr-3 filler.

3. The deleterious phases such as Laves and/or $\delta$ had not been observed in the weld zone of these fillers. Intrigued information on the absence or reduction of deleterious phases could be achieved due to current pulsing and on employing the appropriate fillers which have lower or nil concentrations of $\mathrm{Nb}, \mathrm{Fe}$.

4. The greater hardness at the weld zone of ERNiCrMo-4 weldments could be well attributed to the formation of hard, inter-metallic compounds such as $\mathrm{NbC}$, (Nb, $\mathrm{Ti}) \mathrm{C}$, and $\mathrm{Ni}_{3}(\mathrm{~A} 1, \mathrm{Ti})$.

5. Tensile fractures were observed at the weld zone for the ERNiCr-3 weldments and at the parent metal of Inconel 718 for ERNiCrMo-4 weldments. The tensile results of ERNiCrMo-4 weldments clearly conveyed that the weld strength is higher than that of the base metal strength. Also the results supported the absence or reduction of deleterious phases at the weld zone. Lower tensile values observed at ERNiCr-3 weldments could be due to the absence or evaporation of lowmelting phases.

6. Charpy V-notch impact studies had shown that the ERNiCr-3 weldments have better impact energy compared to the ERNiCrMo-4 weldments. This is due to the lower hardness values observed at the weld zone employing ERNiCr-3 filler.
Hence the present study recommends the use of ERNiCrMo-4 filler for joining Inconel 718 plates using multipass PCGTA welding owing to the absence of deleterious phases and also due to the improvement in weld properties.

Acknowledgments The authors would like to sincerely acknowledge Aeronautical Research \& Development Board (AR \& DB), Govt. of India for funding this project. The authors wish to convey their sincere thanks to Mr. Natarajan, Delta Wear Tech Engineers Pvt. Ltd. Chennai, for providing the welding facilities. The authors are also grateful to DST-FIST for funding toward Instron Universal Testing Machine facility at VIT University.

\section{References}

[1] J. Gordine, Some Problems in Welding Inconel 718, paper present in AWS Spring Meeting, San Francisco, California, 1971

[2] W.D. Cao, R. Kennedy, Superalloys 2004 (TMS, Warrendale, 2004), pp. 91-99

[3] R.G. Thompson, B. Radhakrishnan, D.E. Mayo, in Superalloy 718-Metallurgy and Applications, ed. by E.A. Loria (TMS, Warrendale, 1989), pp. 437-455

[4] M. Qian, J.C. Lippold, Acta Mater. 51, 3351 (2003)

[5] M. Prager, C.S. Shira, Welding of Precipitation Hardening Nickel Based Alloys (Welding Research Council, Bulletin No. 128, New York, 1968)

[6] G.D. Janaki Ram, A. Venugopal Reddy, K. Prasad Rao, G. Madhusudhan Reddy, Sci. Technol. Weld. Join. 9, 390 (2004)

[7] S.G.K. Manikandan, D. Sivakumar, K. Prasad Rao, M. Kamaraj, Mater. Sci. Forum 710, 614 (2012)

[8] W.J. Mills, Weld. Res. Suppl. 76, 113 (1987)

[9] C.H. Radhakrishna, K. Prasad, Rao. J. Mater. Sci. 32, 1977 (1997) 
[10] R.G. Thompson, D.C. Mayo, B. Radhakrishnan, Metall. Trans. A 22, 557 (1991)

[11] R.G. Thompson, D.C. Mayo, B. Radhakrishnan, Metall. Trans. A 22, 887 (1991)

[12] L. Nastac, D. Stefanescu, Metall. Mater. Trans. 27, 4075 (1996)

[13] M.J. Cieslak, T.J. Headley, G.A. Knorovsky, A.D. Romig, T. Kollie, Metall. Trans. A 21, 479 (1990)

[14] J.W. Prybylowski, R.G. Ballinger, Corrosion 43, 111 (1987)

[15] R.G. Carlson, J.F. Radavich, in Superalloy 718-Metallurgy and Applications, ed. by E.A. Loria (TMS, Warrendale, 1989), pp. 79-95

[16] W. Zhang, L. Liu, T. Huaung, Z. Yu, F. Fu, Rare Met. 28, 633 (2009)

[17] W. Zhang, L. Liu, Rare Met. 31, 541 (2012)

[18] G.D. Janaki Ram, A. Venugopal Reddy, K. Prasad Rao, G. Madhusudhan Reddy, J. Mater. Sci. 40, 1497 (2005)
[19] G.D. Janaki Ram, A. Venugopal Reddy, K. Prasad Rao, G. Madhusudhan Reddy, J.K.S. Sundar, J. Mater. Process. Technol. 167, 73 (2005)

[20] G.D. Janaki Ram, A. Venugopal Reddy, K. Prasad Rao, G. Madhusudhan Reddy, Pract. Metallogr. 42(10), 481 (2005)

[21] G.D. Janaki Ram, A. Venugopal Reddy, K. Prasad Rao, G. Madhusudhan Reddy, Mater. Sci. Technol. 21, 1132 (2005)

[22] G.D. Janaki Ram, A. Venugopal Reddy, K. Prasad Rao, G. Madhusudhan Reddy, Mater. High Temp. 23, 29 (2006)

[23] G.D. Janaki Ram, A. Venugopal Reddy, K. Prasad Rao, G. Madhusudhan Reddy, Trans. Indian Inst. Met. 59, 87 (2006)

[24] J.N. DuPont, J.C. Lippold, S.D. Kiser, Welding Metallurgy and Weldability of Nickel-Base Alloys (Wiley, New Jersey, 2009)

[25] J.R. Davis, Tensile Testing, 2nd edn. (ASM International, Ohio, 2004) 